\title{
Colour keys to emotion in management of children and intellectual distraction using coloured games in dental environment for children
}

\author{
Rajakumar ${ }^{1 *}$, Kavitha Ramar $^{2}$ and Revanth MP \\ ${ }^{1}$ MDS, SRM Dental College and Hospital, New no 22/old no12, Veda Giri Street, Alandur, Chennai- \\ 600016, Tamil Nadu, India \\ 2MDS, SRM kattangulathur Dental College and Hospital, Tamil Nadu, India \\ 3BDS, Ragas Dental College And Hospital, Uthandi, Tamil Nadu, India
}

\section{Abstract}

Aim and objective: Dentistry for children is not difficult but is different from what is practiced for adults. The children reacts to differently to people and places around them. Anxiety is an emotional state that helps normal individual defend themselves against a variety of threats and Dental anxiety refers to patients specific response towards dental suitation-associated stress. so the aim is to evaluate the anxiety related management of the children using intellectual mind game of the individual

Study design: The background of the study is to evaluate and study the effectiveness of anxiety control of children using colour distraction between 5 and 12 yrs of age group as one part and the intellectual distraction of children between the same age group using buchanan facial imaging scale and intellectual coloured game chart

Results and conclusions: lowering of anxiety was noticed in the children obtained the favorite colours in the dental environment and easy distraction can be achieved using intellectual gamings.

\section{Introduction}

Anxiety and fear for dental treatment amongst children of various age groups is recognized to be a major public health dilemma. Most children do not cooperate during dental procedures and are sometimes difficult to manage in a normal clinical setup [1]. The attractiveness of the external environment in the dental operatory has been shown to be significantly associated with higher perceived quality and satisfaction, Thus Environmental elements such as colors that produce positive feelings can reduce anxiety and fear. This reports higher positive interaction and reduction in patient anxiety level and to increase cooperativeness. Hence to explain the co-relation and cooperation of the child in the dental office various colors were displayed to sight of the child patient. This study is done to explain the preferences of dental environment with different colures for various age groups and to explain the effect of intellectual distraction [2] during complicated dental procedures. And the child's perception of

\section{More Information}

*Address for Correspondence: Dr. Rajakumar S, MDS, SRM Dental College and Hospital, New no 22/old no12, Veda Giri Street, Alandur, Chennai, 600016, Tamil Nadu, India, Tel: 9841654642 ; 044-22344642 Email: drsrkmds1986@gmail.com

Submitted: 12 August 2019

Approved: 19 August 2019

Published: 20 August 2019

How to cite this article: Rajakumar S, Ramar $\mathrm{K}$, Revanth MP. Colour keys to emotion in management of children and intellectual distraction using coloured games in dental environment for children. J Clin Adv Dent. 2019; 3: 001-003.

doi:10.29328/journal.jcad.1001009

Copyright: @ 2019 Rajakumar S, et al. This is an open access article distributed under the Creative Commons Attribution License, which permits unrestricted use, distribution, and reproduction in any medium, provided the original work is properly cited

Keywords: Emotions; Intellectual coloured games; Buchanan facial imaging scale

D) Check for updates the dental environment as a significant factor causing dental anxiety [3].

The background of the study is to evaluate and study the effectiveness of anxiety control of children using colour distraction between 5 and 12 yrs of age group as one part and the intellectual distraction of children between the same age group using buchanan facial imaging scale and intellectual coloured game chart $[2,3]$.

\section{Methodology used for colour related emotions in children}

Child friendly colour in pediatric dentistry are chosen to be blue, green, violet, yellow, red, and black [3].

For this survey 300 children were chosen out of which 104 children of the younger age group were graded as anxious and 52 children as non-anxious. 56 children of the older age group were anxious and 88 children were non anxious (Figure 
1) using facial image cale (FIS) used by buchanan an niven in 2002 [4].

\section{Methodology for intellectual coloured games}

The intellectual coloured game study was conducted in the department of paediatric and preventive dentistry at SRM katankulathur dental college, Chennai. A total of 50 children in the age group of 5 to 8 years ( 25 male and 25 female) were surveyed with parental consent. The anxieties of the children were measured using the Buchanan facial image scale (Figure 3 ) prior to the procedure. The children were asked to play the ICG by counting the number of the particular coloured figures as told by the dentist.

\section{Effectiveness of intellectual distraction [2]}

This part of the study aims to explain the effect of an intellectual colored game (ICG) (Figure 2) on the severity of gag reflex (GR) and anxiety in children during dental alginate impression [5]. Forty-one children, aging between 5 and 12 years, having a GR varying from normal to moderate had upper

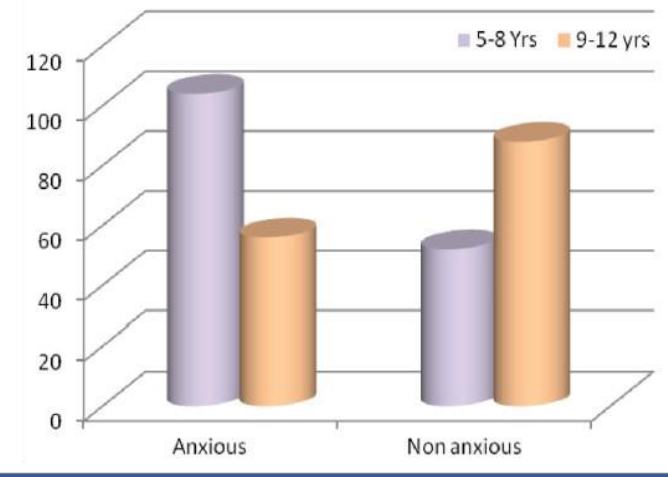

Figure 1: Bar diagram showing level of anxiousness among children of age 5-8 and 9-12.

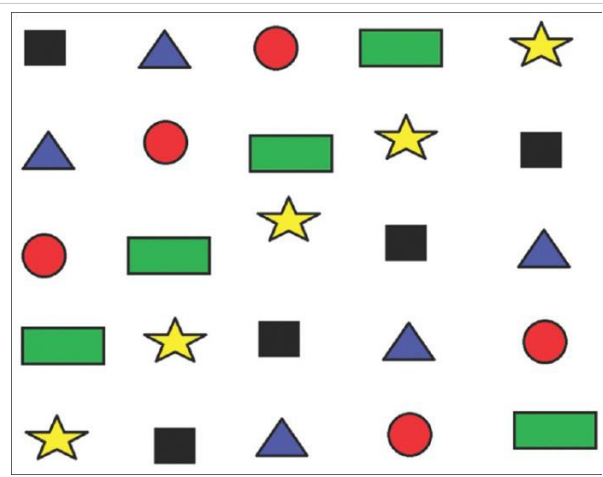

Figure 2: Intellectual coloure game.

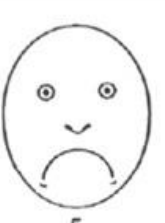

5

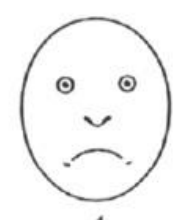

4

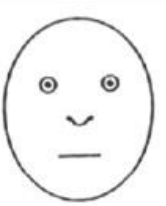

3

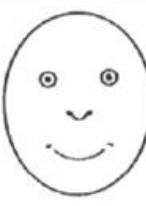

2

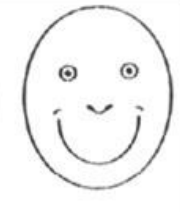

1
Figure 3: Buchanan facial imaging scale. alginate impressions. The children's anxiety was evaluated with a facial image scale (FIS) before impression assumed as (T0) and after first failed impression assumed as (T1), then, after playing an intellectual colored game (ICG) it I assumed as (T2), while taking an upper alginate impression.

The GR grade was evaluated before the impression procedure using the classification of gagging problem index (Saita et al.).

\section{G1: Normal gagging}

G2: Mild gagging

G3: Moderate gagging

\section{G4: Severe gagging}

\section{G5: Very severe gagging}

\section{Results}

On the basis of this study, we conclude that color distraction is one of the most safest and easiest way of behavior management and anxiety control measure in pediatric dentistry. Use of colors like yellow, blue and white are associated with a marked reduction in anxiety in children an reuction in gaging [3]. Based on these conclusions a pilot study to analyze the effectiveness of intellectual colored games during simple restorative procedures was performed as follows.

Before any impression taking, none of the children had a GR more severe than Stage 3 whereas 5 children (11.9\%) had high anxiety as assessed by FIS scores of 5 . Initial GR was not significantly associated with the final success of the impression process. FIS scores after the first failed impression attempt were not associated with final impression success with the ICG, whereas final impression success was strongly associated with final FIS score. This study proves that there is a significant decrease in anxiety and gag reflex following visual distraction using colours.

About 30 children were seen in the scale of 3 , about 12 children were seen in the scale of 4 and about 8 children in the scale 2. Simple restorative procedures were carried out after the initial assessment and the children were allowed to play the ICG. Facial scale assessment was done in between the procedures.

\section{Discussion}

Based on various research articles explaining the preferences of dental environment we observed that a large group of children preferred colored environment to basic dental clinics [5]. About $76 \%$ of the children are seen to prefer cartoon designs on the walls of the dental operatory; $82 \%$ prefer toys in the dental operatory; $94 \%$ prefer a scented operatory. Studies suggest that walls with pictures or artwork 
were preferred among the younger age group (6-8 years) when compared to bare walls in the older age group (9-12 years) and figure 4 shows 5 to 8 age group of children choosen yellow colour was more anxious followed by green , pink and blue colors.and anxious level patter followed by 9 myo 12 age group children were also noticed to be same namely yellow with more anxious followed by green , pink and blue colours. whereas all the age groups selected red and black shows a least anxious level and better cooperation.

\section{Conclusion}

Thus we conclude that color remains the most effective way of anxiety control and distraction. However the lack of uniformity and ambiguity needs attention to make the method practically satisfactory.

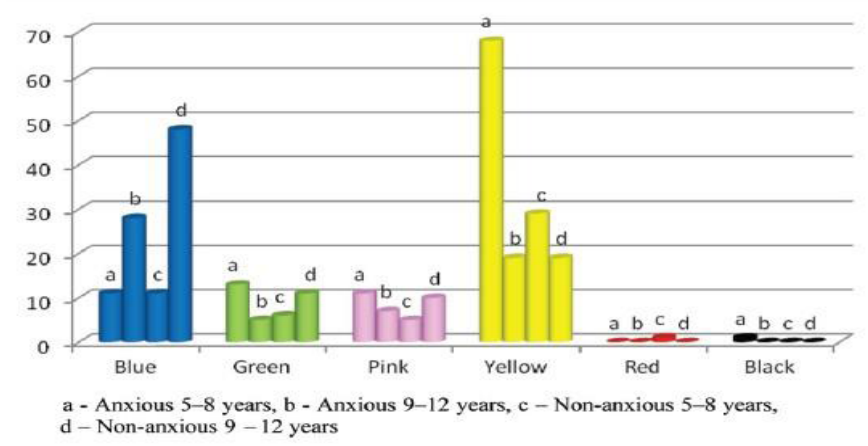

Figure 4: Different age group of children showing different level of anxiousness according to the different coloured aprons.
The study requires further increase in the sample size to evaluate the effectiveness of color distraction during regular dental procedures and also to identify the intellectual development of the children in the dental behavior using colour distraction methods. Finally the study revealed that there was a significant improvement in the facial scale in about 60 percent of the children and stagnation of the scale value in the rest 40 percent of the children. No difference with sex was revealed.

\section{References}

1. Jayakaran TG, Rekha CV, Annamalai S, Baghkomeh PN, Sharmin DD. Preferences and Choices of a child concerning the environment in a pediatric dental operator. Dent Res J (Isfahan). 2017; 14: 183-187. PubMed: https://www.ncbi.nlm.nih.gov/pubmed/28702059

2. Debs NN, Aboujaoude S. Effectiveness of intellectual distraction on gagging and anxiety management in children: a prospective clinical study. J Int Soc Prev Community Dent. 2017; 7: 315-320. PubMed: https://www.ncbi.nlm.nih.gov/pubmed/29387614

3. Umamaheshwari N, Asokan S, Kumaran TS. Child Friendly Colors In A Pediatric Dental Practice. J Indian Soc Pedod Prev Dent. 2013; 31 225-228. PubMed: https://www.ncbi.nlm.nih.gov/pubmed/24262394

4. Shetty RM, Khandelwal M, Rath S. RMS Pictorial Scale (RMS-PS): an innovative scale for the assessment of child's dental anxiety. J Indian Soc Pedod Prev Dent. 2015; 33: 48-52. PubMed: https://www.ncbi. nIm.nih.gov/pubmed/25572374

5. Asokan A, Kambalimath HV, Patil RU, Maran S, Bharath KP. A Survey of the dentist attire and gender preferences in dentally anxious children. J Indian Soc Pedod Prev Dent. 2016; 34: 30-35. PubMed: https://www. ncbi.nlm.nih.gov/pubmed/26838145 